\section{Estudo da participação de resíduos de manose na migração de células da crista neural torácica pela via dorsolateral em embriões de galinha (Gallus gallus, Linnaeus) 1758}

The participation of mannose residues in thoracic neural crest cells migration by the dorsolateral pathway in chicken embryos (Gallus gallus, Linnaeus) 1758

Etiéli Mara Wendler ${ }^{[a]}$, Chélin Auswald Steclan ${ }^{[b]}$, Luciana de Fátima Chaves de Mello Zischler ${ }^{[\mathrm{cc}[\mathrm{[R]}}$

\section{Resumo}

As células da crista neural (CCN) originam-se da parte dorsal do tubo neural e, de acordo com a via migratória tomada, originam diversos tipos celulares. Pouco se sabe sobre a participação das moléculas glicoconjugadas na migração das CCN. Com o intuito de evidenciar uma possível participação de moléculas manose-terminais na via de migração dorsolateral das CCN de embriões de galinha, foi utilizada a lectina artin M (ligante dessas moléculas). Os resultados obtidos demonstram que, na via dorsolateral de migração da crista neural torácica, há presença de moléculas manose-terminais e sugere-se um possível papel dessas moléculas, especificamente, na migração de células melanocíticas.

Palavras-chave: Crista neural. Melanoblastos. Lectina artin M.

\begin{abstract}
The neural crest cells $(\mathrm{NCC})$ consist of a population that arises from the dorsal part of the neural tube and, according to the migratory pathway, differentiates in a wide range of cell types. Little is known about the participation of glicoconjugate molecules in the NCC migration. To determinate whether mannose residues are present through the dorsolateral migratory pathway of thoracic NCC in chicken embryos we used the artin M lectin, which binds specifically to mannose-terminal molecules. This assay allowed the detection of mannose residues through the dorsolateral pathway of thoracic neural crest migration. It is possible that mannose-terminal molecules have a specific role in the melanocitic lineage migration.
\end{abstract}

Keywords: Neural crest cells. Melanoblasts. Artin M lectin. [a] Graduada em Ciências Biológicas, Pontifícia Universidade Católica do Paraná (PUCPR), Curitiba, PR - Brasil, e-mail: etieli@hotmail.com

${ }^{[b]}$ Mestre em Ciências da Saúde, Universidade Federal do Paraná (UFPR), Depto. de Biologia Celular, Curitiba, PR - Brasil, e-mail: chelin_a_s@hotmail.com

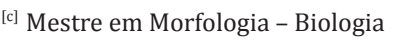
Celular, Pontifícia Universidade Católica do Paraná (PUCPR), Curitiba, PR - Brasil, e-mail: luciana.zischler@ pucpr.br

Recebido: 17/02/2012

Received: 02/17/2012

Aprovado: 12/04/2012

Approved: 04/12/2012 


\section{Introdução}

As células da crista neural se originam da ectoderme neural da parte dorsal do tubo neural, desprendem-se do tubo e migram para longe dessa estrutura $(1,2)$. De acordo com o nível axial de origem e com a via migratória tomada, as células da crista neural originam uma ampla variedade de células, como ossos da face, melanócitos, músculo liso no coração e componentes do sistema nervoso periférico (SNP) (2). Existem duas vias de migração tomadas pelas células da crista neural: a via de migração ventral, que ocorre entre o tubo neural e os somitos, e a via de migração dorsolateral, que ocorre entre a ectoderme e os somitos (dermatomiótomo). Enquanto a crista neural vagal apresenta três ondas de migração (via dorsolateral, via ventral, via dorsolateral), a crista neural torácica apresenta apenas duas ondas migratórias (3). A primeira acontece por via ventral, e as células se diferenciam como células da glia e neurônios do SNP. A segunda onda de migração acontece ao longo da via dorsolateral, e as células diferenciam-se em melanócitos $(4,5)$.

Ao migrarem, as células da crista neural encontram um ambiente rico em matriz extracelular. Nesse ambiente, as células seguem as vias de migração já citadas e que têm sido explicadas por dois modelos: 1) as vias de migração podem ser determinadas por características externas, encontradas no ambiente por onde as células estão migrando, ou 2) por características intrínsecas das células da crista neural (6). 0 primeiro modelo de migração citado e o mais aceito é conhecido como modelo dirigido pelo ambiente, proposto por Le Douarin e Teillet (7). Esse modelo propõe que as células da crista neural sejam multipotentes e migrem ao acaso, pelas vias ventral ou dorsolateral. Sua diferenciação ocorre de acordo com as influências recebidas do ambiente por onde migram ou do ambiente do seu destino final. 0 segundo modelo, dirigido pelo fenótipo, tem sido sustentado por estudos mais recentes. Esse modelo prediz que, ao deixar o tubo neural, as células da crista neural já estão especificadas para uma determinada linhagem, e tal especificação leva as células a tomarem vias migratórias que podem ser exploradas de acordo com suas características intrínsecas $(4,8)$. Portanto, de acordo com esse modelo, as propriedades migratórias específicas das células determinam a distribuição final dos derivados da crista neural.

A interação das células da crista neural com a matriz extracelular é um dos mecanismos mais importantes para a migração dessas células, mas não é suficiente para explicar completamente a complexidade espacial e temporal da migração (9). Para que ocorra a interação das células da crista neural com os componentes da matriz extracelular, faz-se necessária a expressão de receptores de membrana específicos, o que parece ocorrer um pouco antes ou logo após a liberação das células do tubo neural (4). Diferentes moléculas da matriz extracelular estão distribuídas ao longo dos caminhos migratórios das células da crista neural, formando um substrato que pode permitir a migração dessas células ou desempenhar um papel inibitório, impedindo-as de entrar em determinadas áreas do embrião.

Oakley et al. (10) mostraram que há uma redução da proteoglicana condroitin sulfato e de moléculas ligantes de PNA (lectina extraída do amendoim, com especificidade para ligar resíduos de galactose a partir do estágio 19 do desenvolvimento - que precede a migração da crista neural pela via dorsolateral). Então, já que condroitin sulfato e moléculas galactose-terminais (ligantes a PNA) são inibidoras de migração e estão relacionadas ao atraso da entrada das células da crista neural no caminho dorsolateral, isso mostra que os precursores de melanócitos são especificados antes de iniciarem a migração.

Freitas, Ferreira e Faraco (11) realizaram estudos sobre a presença de glicoconjugados ligantes a PNA na matriz extracelular de embriões de galinha, ao longo da via ventral de migração das células da crista neural. 0 estudo foi realizado em diferentes níveis axiais e foi observado que, onde a marcação de PNA esteve fraca ou quase ausente, houve migração das células da crista neural. Demonstrou-se, com esse estudo, que tanto as células de linhagem neuronal (via ventral) quanto os melanoblastos (via dorsolateral) são capazes de migrar apenas por regiões com pequena concentração de glicoconjugados PNApositivos. A presença constante de glicoconjugados PNA-positivos nas regiões ventrais de embriões de Leghorn branca, durante a migração dorsolateral no nível do tronco, sugere o papel inibitório dessas moléculas no povoamento ventral por melanócitos.

Estudos realizados anteriormente no nosso laboratório tiveram o intuito de detectar resíduos de manose ao longo da via ventral de migração da crista neural torácica em embriões de galinha. Para tanto, foi utilizada a lectina artin $\mathrm{M}$, ligante de moléculas manose-terminais e extraída da semente de Jaca (Artocarpus integrifolia). Os resultados obtidos demonstraram que não há presença de resíduos de manose na via ventral de migração 
da crista neural torácica, sugerindo que essas moléculas não participam desses eventos migratórios.

Portanto, este trabalho teve como objetivo detectar a presença de resíduos de manose ao longo da via dorsolateral de migração das células da crista neural torácica de embriões de galinha (Gallus gallus), entre os estágios 20 e 28 do desenvolvimento, utilizando a lectina artin M.

\section{Material e métodos}

\section{Obtenção e fixação dos embriões}

Ovos embrionados de galinha (Gallus gallus) foram incubados em chocadeira umidificada a $38^{\circ} \mathrm{C}$, até atingirem os estágios 20, 22-23, 24 e 28 do desenvolvimento embrionário. Os embriões foram, então, retirados de suas cascas, colocados em solução salina tamponada com fosfato (PBS) e estagiados segundo Hamburger (12). Após o estagiamento, os embriões foram mantidos por 1 (uma) hora no fixador Bouin.

\section{Desidratação, inclusão em parafina histológica e microtomia}

Após a fixação, os embriões foram lavados e armazenados em etanol 70\%, para eliminar resíduos do fixador. Para obtenção do nível torácico, os embriões foram cortados entre os somitos 18 e 23. Os segmentos de embrião obtidos foram desidratados em série crescente de etanol 70 a 100\%. Os segmentos foram incluídos em parafina histológica e os blocos foram cortados transversalmente em micrótomo Minot, resultando em cortes com espessura de $6 \mu \mathrm{m}$. Os cortes foram montados em lâminas com albumina, as quais foram secas em estufa e, depois, armazenadas em temperatura ambiente, em local protegido de poeira até as próximas etapas (coloração com hematoxilina e marcação com artin M).

\section{Lâminas coradas com hematoxilina}

\section{Coloração com hematoxilina}

Para realizar a coloração, as lâminas foram previamente desparafinizadas com xilol e reidratadas em série decrescente de etanol 100 a 70\%. A fim de verificar se a morfologia dos embriões foi preservada de maneira adequada, as lâminas foram lavadas rapidamente com água e coradas com hematoxilina por 30 segundos, sendo, em seguida, lavadas em água corrente.

\section{Desidratação, diafanização e montagem das lâminas}

As lâminas coradas foram desidratadas em série crescente de etanol 70 a 100\%. A diafanização foi realizada com xilol. As lâminas foram montadas com Permount e lamínula.

\section{Documentação fotográfica}

As imagens foram obtidas em microscópio Olympus BX50, acoplado ao software Image Pro Plus, no laboratório de patologia experimental da PUCPR.

\section{Detecção de resíduos de manose pela lectina $\operatorname{artin} \mathrm{M}$}

As lâminas selecionadas para realizar a marcação com $\mathrm{KM}^{+}$-biotinilado foram desparafinizadas e reidratadas, como no passo 3 , no entanto, não foram coradas com hematoxilina.

\section{Lavagem dos cortes}

Após a reidratação, as lâminas foram lavadas em PBS, por 2 minutos, em PBS contendo glicina 0,1M, por 5 minutos, e, novamente, em PBS, por 2 minutos.

\section{Pré-incubação de artin M em PBS contendo D-manose 0,2 M}

O PBS contendo artin M-biotinilado foi pré-incubado com D-manose $0,2 \mathrm{M}$, por 45 minutos, a uma temperatura de $37^{\circ} \mathrm{C}$, para realizar o controle de bloqueio da ligação de artin M.

\section{Marcação dos cortes com artin M}

Para a marcação de resíduos de manose nos cortes de embrião, as lâminas foram incubadas com artin M-biotinilada na diluição de $20 \mu \mathrm{l} / \mathrm{ml}$, por 45 
minutos, em temperatura ambiente. Os controles foram realizados utilizando-se apenas PBS e PBS contendo artin $\mathrm{M}$ pré-incubado, com D-manose a 0,2 M $(20 \mu \mathrm{l} / \mathrm{ml})$, ambos por 45 minutos e em temperatura ambiente. As lâminas foram posteriormente lavadas com PBS, por três vezes.

\section{Detecção dos resíduos de manose e montagem das lâminas}

Para a detecção dos resíduos de manose reconhecidos por artin M-biotinilada na via dorsolateral de migração da crista neural, foi utilizado Estreptoavidina-FITC $(1: 40 ; 3 \mu \mathrm{l} / \mathrm{ml})$. As lâminas foram incubadas com a solução por 45 minutos, em temperatura ambiente e em câmara escura. Após a incubação, as lâminas foram lavadas com PBS por oito vezes e montadas com Fluormount-G e lamínula.

\section{Documentação fotográfica}

As imagens foram capturadas em microscópio de epifluorescência Axiophot (ZEISS), acoplado ao software Case Data Manager Expo (UFPR).

\section{Resultados}

A coloração dos cortes de embriões pela hematoxilina mostrou a preservação morfológica do tubo neural, dos dermatomiótomos e da notocorda (Figuras 1A, 2A, 3A, 4A). Essas estruturas embrionárias são fundamentais para a correta localização da via migratória analisada, facilitando a visualização da marcação de moléculas manose-terminais pela lectina $\operatorname{artin} \mathrm{M}$.

\section{Embriões no estágio 20}

Nesse estágio, observou-se a marcação de resíduos de manose pela lectina artin $\mathrm{M}^{+}$no dermatomiótomo e na lâmina basal que envolve o tubo neural e a notocorda (Figura 1B). A marcação da via dorsolateral de migração da crista neural só pode ser visualizada no aumento de 40x (Figuras 1C e 1D), pois é uma marcação fraca em relação àquela observada no aumento imediatamente inferior. Na figura 1C, observam-se os resíduos de manose marcados por artin M na matriz extracelular da região dorsal do tubo neural, onde, de acordo com Serbedzija, Bronner-Fraser e Fraser (13), as células da crista neural são encontradas no início de sua onda migratória pela via dorsolateral. Observa-se, também, a fraca marcação ao longo da via dorsolateral, onde ainda há poucas células em migração (Figura 1D).

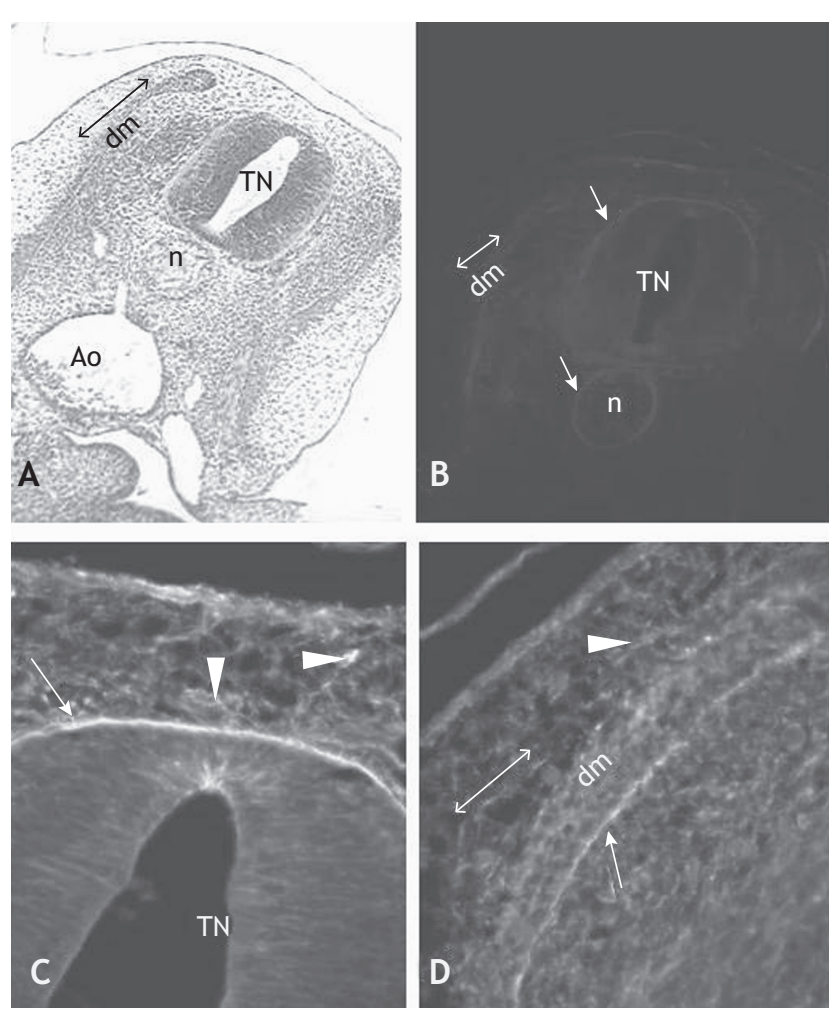

Figura 1 - Cortes transversais de embrião de galinha no estágio 20 de desenvolvimento. A - Corte corado com hematoxilina, demonstrando a preservação da morfologia. Aumento: 10x. Tubo neural (TN), notocorda (n), aorta dorsal (Ao), dermatomiótomo (dm). A via dorsolateral de migração (seta dupla) ocorre entre 0 dermatomiótomo e a ectoderme de revestimento externo (seta). B - Imagem obtida em microscopia de fluorescência, demonstrando a marcação de resíduos de manose pela lectina artin M no dermatomiótomo, na lâmina basal do tubo neural e da notocorda (setas). Aumento: 10x. C - Observar que, no aumento de 40x, é possível visualizar a marcação de resíduos de manose na matriz extracelular da porção dorsal do tubo neural (cabeças de seta). A seta indica a marcação da lâmina basal do tubo neural. D - Observar a marcação fraca, por $\operatorname{artin} M$, na via de migração dorsolateral da crista neural (cabeça de seta).

\section{Embriões no estágio 22-23}

Em aumento de 10x, ainda é possível observar marcação, pela lectina artin M, na lâmina basal que envolve o tubo neural e na que envolve a aorta dorsal. No entanto, não houve marcação na lâmina 
basal da notocorda, como no estágio 20 (Figura 2B). No aumento de 20x, é possível observar que existe marcação na matriz extracelular da porção dorsal do tubo neural, porém, mais fraca que a marcação da lâmina basal do tubo neural (Figura 2C). Em aumento de 40x, foi possível observar que há fraca marcação na via dorsolateral de migração das células da crista neural. Nesse aumento, também é evidenciada a marcação do dermatomiótomo (Figura 2D).

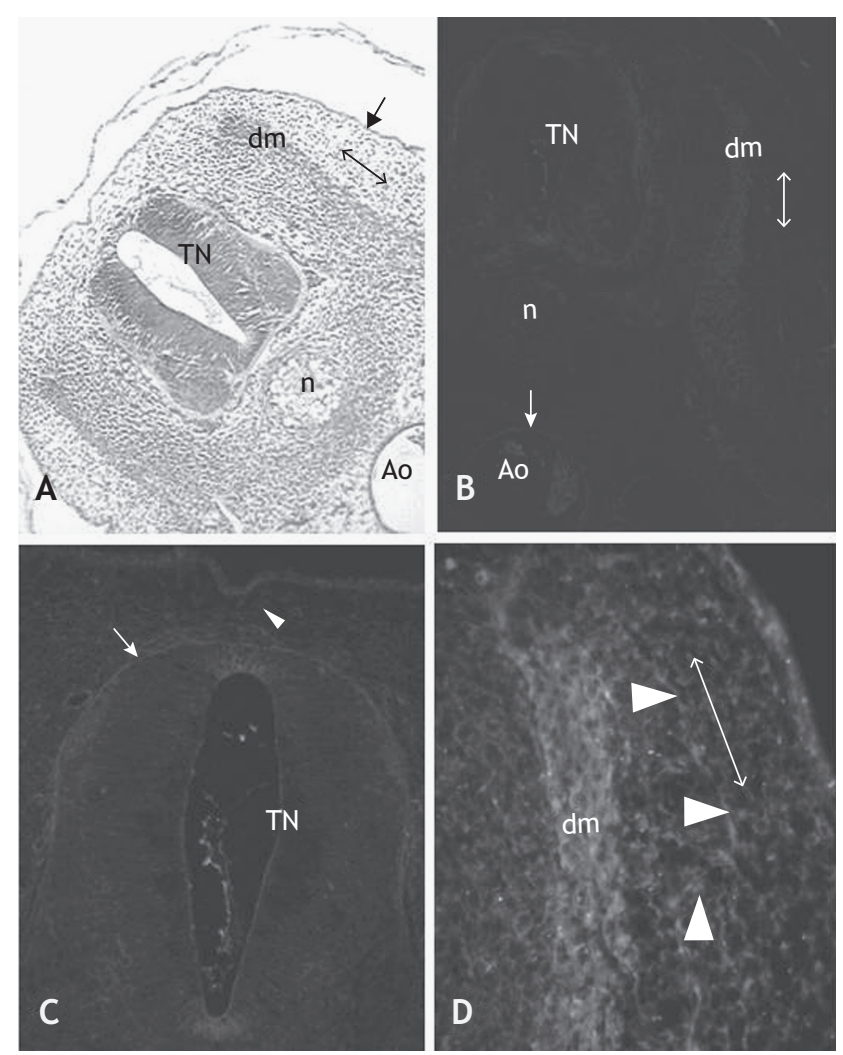

Figura 2 - Cortes transversais de embrião de galinha no estágio 22-23 de desenvolvimento. A - Coloração com hematoxilina, demonstrando a preservação da morfologia. Aumento: 10x. Tubo neural (TN), notocorda (n), aorta dorsal (Ao), dermatomiótomo $(\mathrm{dm})$, via dorsolateral de migração (seta dupla), ectoderme de revestimento (seta). B - Observa-se a redução de marcação de resíduos de manose, pela lectina artin M, na lâmina basal do tubo neural e da aorta dorsal (setas) e a ausência de marcação na lâmina basal da notocorda. Aumento: 10x. C - Observar que, no aumento de 20x, a marcação na matriz extracelular da porção dorsal do tubo neural é fraca (cabeça de seta). A seta indica a fraca marcação da lâmina basal do tubo neural. D - Observar a marcação, por artin M, no dermatomiótomo e na via de migração dorsolateral da crista neural (cabeças de seta). Aumento: 40x.

\section{Embriões no estágio 24}

Nesse estágio, nos aumentos de 20x e 40x, observou-se diminuição da marcação pela lectina artin M na lâmina basal do tubo neural e dermatomiótomo, quando comparada com o estágio 22-23. Observou-se, também, a marcação fraca na via dorsolateral de migração da crista neural e ausência de marcação na matriz extracelular da porção dorsal do tubo neural (Figuras 3B e 3C). Observou-se a ausência de marcação no controle negativo (Figura 3D).

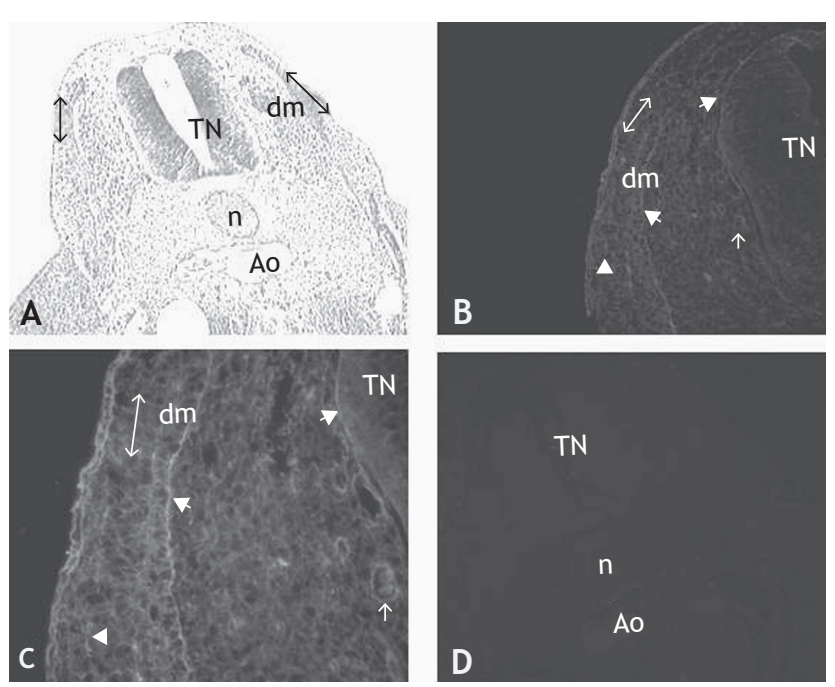

Figura 3 - Cortes transversais de embrião de galinha no estágio 24 de desenvolvimento. A - Coloração com hematoxilina, demonstrando a preservação da morfologia. B - Observar a marcação fraca, pela lectina artin $M$, na lâmina basal do tubo neural e dermatomiótomo (setas) e dos capilares sanguíneos (seta aberta). Observar a marcação fraca na via dorsolateral de migração da crista neural (cabeça de seta). Aumento: 20x. C - Observar, em aumento de 40x, detalhes das marcações citadas na figura B. D - Controle negativo. Observar a ausência de marcação. Aumento: 10x.

\section{Embriões no estágio 28}

Houve grande redução na marcação dos resíduos de manose pela lectina artin $\mathrm{M}$, nesse estágio. Notou-se a ausência de marcação na lâmina basal do tubo neural e da notocorda, em aumento de 10x (Figura 4B). Não foi observada marcação na via dorsolateral de migração da crista neural e, além disso, houve redução da marcação no dermatomiótomo, em aumento de 20x (Figura 4C). Em aumento de 40x, a ausência de marcação na lâmina basal do tubo neural e dos vasos sanguíneos e, principalmente, a ausência de marcação na matriz extracelular da região dorsal do tubo neural foram ressaltadas. A ausência de marcação é evidenciada pela autofluorescência das células do sangue (Figura 4D). 


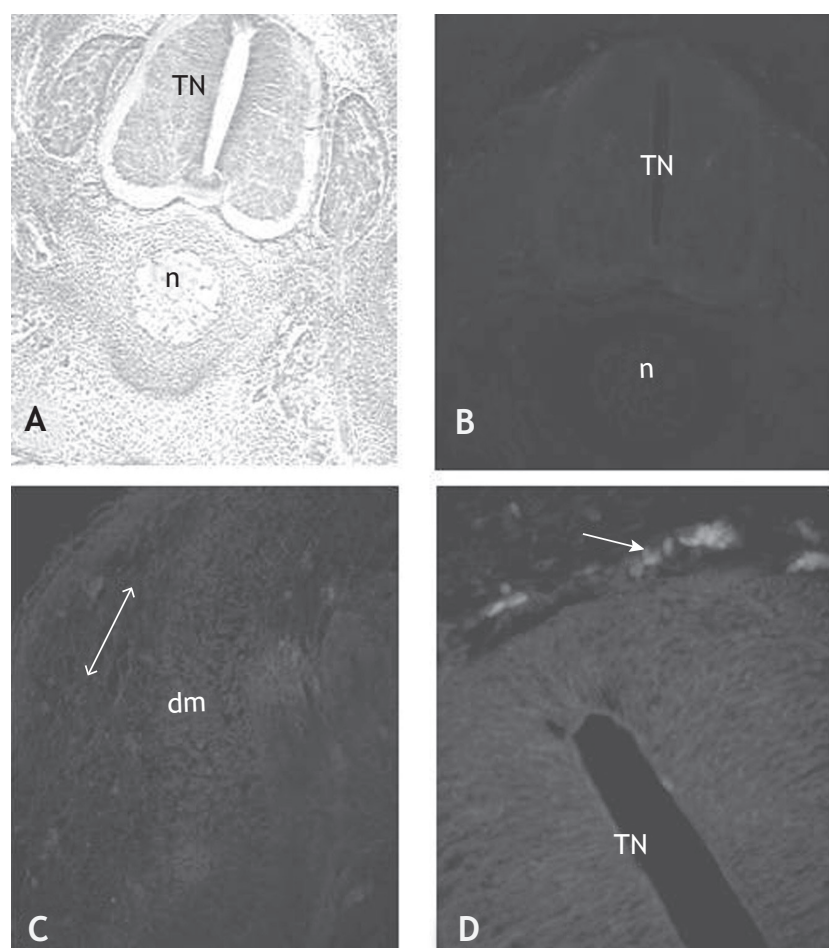

Figura 4 - Cortes de embrião de galinha no estágio 28 do desenvolvimento. A - Coloração com hematoxilina, demonstrando a morfologia preservada. B - Observar a grande redução na marcação dos resíduos de manose pela lectina artin M. Notar a ausência de marCação na lâmina basal do tubo neural e da notocorda. Aumento: 10x. C - Observar a ausência de marcação na via dorsolateral de migração da crista neural e a redução da marcação no dermatomiótomo. Aumento: 20x. D - Observar a ausência de marcação na lâmina basal do tubo neural e dos vasos sanguíneos. Ausência de marcação na matriz extracelular da região dorsal do tubo neural. A seta indica a autofluorescência das células do sangue. Aumento: 40x.

\section{Discussão}

A migração das células da crista neural se inicia quando o tubo neural se fecha durante a neurulação, seguindo uma orientação anteroposterior (1, 14). Serbedzija, Bronner-Fraser e Fraser (13) mapearam a dinâmica temporal de migração da crista neural torácica em ambas as vias, ventral e dorsolateral. A migração ventral se inicia 24 horas antes do início da migração dorsolateral (4). Uma explicação para o atraso na migração dorsolateral é a presença de fatores inibitórios. A proteoglicana condroitin sulfato e moléculas que se ligam a PNA (ligantes de moléculas galactose-terminais) estão relacionados com a inibição da migração das células da crista neural. Esses dados foram demonstrados por Oakley et al. (10), que detectaram uma redução da proteoglicana condroitin sulfato e de moléculas ligantes a PNA no caminho dorsolateral a partir do estágio 19 do desenvolvimento, quando as células da crista neural entram na via de migração dorsolateral. Com base em observações de embriões de galinhas com padrão normal de pigmentação, que apresentam melanócitos somente na pele, como a raça Leghorn, e em embriões de galinha Sedosa, que apresentam melanócitos em órgãos internos, além da pele (15), Freitas, Ferreira e Faraco (11) observaram que, em galinhas Leghorn, durante o período de migração ventral, o caminho dorsolateral sempre se apresenta muito marcado pelo PNA. No momento em que a migração ventral está se encerrando, a marcação pelo PNA na região correspondente à via ventral aumenta bastante, e as células da crista neural começam a invadir a via dorsolateral. Nesse momento, a marcação pelo PNA na via dorsolateral vai desaparecendo à medida que a migração da crista neural progride. Nos embriões de galinha Sedosa, além de as células migrarem dorsolateralmente, atingindo a pele, elas também migram ventralmente e se desviam do caminho dorsolateral pela região abaixo da extremidade ventral do somito, a qual se encontra livre de marcação pelo PNA. Os glicoconjugados de matriz extracelular ligantes a PNA estão, dessa forma, envolvidos nos diferentes padrões de migração dorsolateral (de melanoblastos) observados em embriões de galinha (11).

A utilização da lectina artin M (ligante de moléculas manose-terminais) anteriormente, em nosso laboratório, teve o intuito de detectar moléculas manose-terminais ao longo da via ventral de migração da crista neural torácica em embriões de galinha. No entanto, a ausência de marcação de resíduos de manose demonstrou que essas moléculas não possuem papel na dinâmica de migração da crista neural torácica na via ventral. Entretanto, no presente estudo, houve a marcação por $\mathrm{KM}^{+}$ao longo da via de migração dorsolateral torácica (Figuras 1D, 2D, 3C). Esse resultado, combinado com a ausência de marcação observada na via ventral e considerando que a entrada da crista neural torácica na via dorsolateral de migração depende de sua especificação na linhagem melanocítica (16), pode sugerir que os resíduos de manose desempenham um papel específico na migração de melanoblastos. Outro dado que reforça essa sugestão é a ausência de marcação por artin $\mathrm{M}$ a partir do estágio 28 (Figura 4C), quando a migração por essa via é finalizada e os melanoblastos já atingiram seu destino final (15). No presente estudo, a impossibilidade de utilizar marcadores específicos para células da crista neural (anticorpo HNK-1) ou para melanoblastos (soro Smith Line) impede a localização exata dessas moléculas (se estão difusas na matriz extracelular ou envolvendo as células da crista neural). Além disso, o uso da lectina artin M 
para detecção de resíduos de manose nas vias de migração da crista neural de galinha Sedosa (na qual há migração ventral de melanoblastos) poderá ajudar a esclarecer a participação dessas moléculas na dinâmica de migração das células da crista neural torácica.

Com base nesses dados, sugere-se que, talvez, as moléculas manose-terminais suportem, especificamente, a migração de células melanocíticas.

\section{Conclusão}

Existem resíduos de manose na matriz extracelular dorsal ao tubo neural, por onde as células da crista neural iniciam sua migração, e também ao longo da via de migração dorsolateral da crista neural torácica. Logo, é possível que haja um papel dessas moléculas na migração das células em questão.

\section{Agradecimentos}

À professora Andréa Moreno, pelo suporte técnico e fornecimento de $\mathrm{KM}^{+}$-biotinilado e EstreptoavidinaFITC; a Nereu Barão Segundo, pelo fornecimento de ovos embrionados; à professora Claudia Feijó OrolaniMachado e à doutoranda Patrícia Franchi de Freitas (UFPR), pela utilização do microscópio de epifluorescência; à técnica Ana Paula, do Laboratório de Patologia Experimental da PUCPR, pela utilização do microscópio óptico.

\section{Referências}

1. Dupin E, Real C, Le Douarin N. The neural crest cells: control of neural crest cells fate and plasticity by endthelin-3. An Acad Bra Ciênc. 2001;3(4):533-45.

2. Barembaum M, Bronner-Fraser M. Early steps in neural crestspecification. Semin CellDev Biol.2005;16(6):642-6.

3. Loring JF, Erickson CA. Neural crest cell migratory pathways in the trunk of the chick embryo. Dev Biol. 1987;121(1):220-36.

4. Reedy MV, Faraco CD, Erickson CA. The delayed entry of thoracic neural crest cells into the dorsolateral path is a consequence of the late emigration of melanogenic neural crest cells from the neural tube. Dev Biol. 1998;200(2):234-46.
5. Erickson CA, Goins TL. Sacral neural crest cell migration to the gut is dependent upon the migratory environment and not cell-autonomous migratory properties. Dev Biol. 2000;219(1):79-97.

6. Erickson CA, Reedy MV. Neural crest development: the interplay between morphogenesis and cell differentiation. Curr Top Dev Biol. 1998;40:177-209.

7. Le Douarin NM, Teillet MA. The migration of neural crest cells to the wall of digestive tract in avian embryo. J Embryol Exp Morphol. 1973;30(1):31-48.

8. Henion PD, Weston JA. Timing and patterning of cell fate restriction in the neural crest lineage. Development. 1997;124(21):4351-9.

9. Werhle-Haller B, Weston JA. Receptor tyrosine kinase-dependent neural crest migration in response to differentially localized growth factors. Bioessays. 1997;19(4):337-45.

10. Oakley RA, Lasky CJ, Erickson CA, Tosney KW. Glycoconjugates mark a transient barrier to neural crest migration in the chicken embryo. Development. 1994;120(1):103-14.

11. de Freitas PF, Ferreira Fde F, Faraco CD. PNA-Positive glycoconjugates are negatively correlated with the access of neural crest cells to the gut in chicken embryos. Anat Rec A Discov Mol Cell Evol Biol. 2003;273(2):705-13.

12. Hamburger V. The stage series of the chick embryo. Dev Dyn. 1992;195(4):273-5.

13. Serbedezija GN, Bronner-Fraser M, Fraser ES. A vital dye analysis of the timing and path ways of avian trunk neural crest cell migration. Development. 1989;106(4):809-16.

14. Bronner-Fraser M. Neural crest cell formation and migration in developing embryo. FASEB J. 1994;8(10):699-706.

15. Faraco CD, Vaz SAS, Pàstor MVD, Erickson CA. Hyperpimentation in silkie fowl correlates with abnormal migration of fate-restricted melanoblasts and loss of environmental barrier molecules. Dev Dyn. 2001;220(3):212-25.

16. Erickson CA, Goins TL. Avian neural crest cells can migrate in the dorsolateral path only if they are specified as melanocytes. Development. 1995;121(3):915-24. 